\title{
How I Treat Neuroendocrine Tumors
}

\author{
Aasems Jacob ${ }^{1}$ Gaby Gabriel 2,3 \\ Aman Chauhan ${ }^{1,3}$ \\ 1 Division of Medical Oncology, University of Kentucky, Lexington, \\ Kentucky, United States \\ 2 Department of Radiology, Division of Interventional Radiology, \\ University of Kentucky, Lexington, Kentucky, United States \\ ${ }^{3}$ Division of Medical Oncology, Markey Cancer Center, University of \\ Kentucky, Lexington, Kentucky, United States \\ ${ }^{4}$ Department of Hematology and Oncology, Ochsner Health New \\ Orleans, New Orleans, Louisiana, United States \\ ${ }^{5}$ Department of Surgery, Louisiana State University Health Science \\ Center, New Orleans, Louisiana, United States
}

Ind J Med Paediatr Oncol 2021;42:470-478.
Address for correspondence Aman Chauhan, MD, Department of Medical Oncology, University of Kentucky, 800 Rose Street, Lexington 40536, United States (e-mail: amanchauhan@uky.edu).

\section{Case 1}

A 61-year-old female presented with right hip pain, diarrhea, and weight loss over the past few months. Pelvic X-ray showed lytic lesions in right femoral acetabulum. Computerized tomography (CT) of abdomen showed multiple liver lesions and additional bony metastasis in ribs. Biopsy of a liver lesion showed a metastatic G2 well-differentiated NET with $\mathrm{K}_{\mathrm{i}}-67$ of $10 \%$.

\section{Diagnosis}

$\mathrm{CT}$ and/or magnetic resonance (MR) scans are the commonly utilized imaging modalities for initial evaluation. Multiphasic CT/MRI is helpful in evaluating liver metastasis since NETs are highly vascular and can appear isodense on conventional scans. NETs with unknown primary site should be additionally evaluated with upper and lower endoscopy with attention to the terminal ileum or by CT enterography. Evaluation with somatostatin receptor (SSR)-based imaging, like 68-Ga-DOTATATE positron emission tomography (PET), or Cu-64-DOTATATE (preferred over Indium-111-pentetreotide SPECT), is utilized to assess receptor status for determining benefit of SSR-directed therapy and evaluate suspected metastasis if unclear on initial imaging.
DOI https://doi.org/ 10.1055/s-0041-1732833. ISSN 0971-5851.
(C) 2021. Indian Society of Medical and Paediatric Oncology. All rights reserved.

This is an open access article published by Thieme under the terms of the Creative Commons Attribution-NonDerivative-NonCommercial-License, permitting copying and reproduction so long as the original work is given appropriate credit. Contents may not be used for commercial purposes, or adapted, remixed, transformed or built upon. (https://creativecommons.org/ licenses/by-nc-nd/4.0/)

Thieme Medical and Scientific Publishers Pvt. Ltd., A-12, 2nd Floor, Sector 2, Noida-201301 UP, India 
When symptoms are suggestive of carcinoid syndrome (unclear in this case), the initial biochemical evaluation of choice is 24-hour urinary excretion of 5-hydroxyindoleacetic acid (5-HIAA). The test has $90 \%$ sensitivity and $90 \%$ specificity to detect carcinoid syndrome. ${ }^{4}$ Urinary 5-HIAA level in carcinoid syndrome was found to range between 99 and 2,070 mg/day; however, lower levels may be present with foregut and hindgut tumors. Chromogranin and serotonin levels lack sensitivity and specificity; however, it is useful in foregut, rectal, and pancreatic NETs where 5-HIAA level is not usually elevated. ${ }^{5}$ Plasma 5-HIAA level has not been well validated. Serum VIP (VIPoma), glucagon (glucagonoma), gastrin (gastrinoma), and insulin/pro-insulin/C-peptide (insulinoma) levels are helpful in functional pancreatic NETs.

... 24-hour urine 5-HIAA level was $928 \mathrm{mg} /$ day. While awaiting further workup, what treatment should be given for her symptomatic disease?

\section{Management of Symptoms of Hormone Secretion}

The most common symptoms from functional NETs are flushing and diarrhea and are associated with elevated urinary 5-HIAA. Since $80 \%$ of well-differentiated gastrointestinal (GI)-NETs express SSR, somatostatin analogs (SSA)like octreotide and lanreotide are highly effective in controlling the symptoms. Initial therapy should be with octreotide of 50 to $750 \mu \mathrm{g} /$ day, two to four times a day subcutaneously (typically started at 100-150 $\mu$ g thrice a day with some patients requiring up to $1,500 \mu \mathrm{g} / \mathrm{day}$, although data limited). This not only provides rapid symptomatic relief but also acts as test dose before initiating long-acting depot. After 1 to 2 weeks on short-acting SSA confirming symptomatic relief and absence of adverse reactions, we initiate long-acting depot injections starting with Octreotide intramuscular (IM) depot injection (octreotide long acting release - LAR) 20 to $30 \mathrm{mg}$ at every 4 weeks. Although dose can be decreased to 10 -mg IM at every 4 weeks depending on the response, in our practice, we start at 30-mg IM every 4 weekly dose and usually do not deescalate due to its benefit in tumor stabilization as seen in PROMID randomized clinical trial. ${ }^{6}$ Continue short-acting SSA for the first 2 weeks to maintain therapeutic levels. Temporary exacerbation of symptoms can be treated with additional subcutaneous injections. Lanreotide given 120-mg subcutaneous at every 4 weeks has similar efficacy and tolerability with additional progression-free survival (PFS) benefit and carcinoid syndrome control as noted in CLARINET and ELECT studies. ${ }^{7}$ Phase-II randomized trials have not shown benefit of adding pasireotide, a second-generation SSA along to everolimus. ${ }^{8,9}$

Telotristat ethyl, a serotonin synthesis inhibitor is Food and Drug Administration (FDA)-approved for the management of carcinoid syndrome diarrhea refractory to SSA and is usually very well tolerated. ${ }^{10}$ Low-dose interferon alfa can improve symptoms in patients refractory to SSA. ${ }^{11}$ However, the treatment is rarely used due to its high toxicity profile of fatigue, depression, and flu-like symptoms. Antidiarrheal therapy with loperamide and/or diphenoxylate-atropine should also be considered. Reducing the SSA intervals, and increasing the dose may offer some benefit.
Initial therapy for insulinomas is carbohydrates and diazoxide which inhibit hormone release. For gastrinomas, oral proton pump inhibitors should be considered. SSA can be used in all refractory disease. ${ }^{12}$

... CT chest showed no disease. Upper and lower GI endoscopic evaluation was unremarkable. What is the initial treatment for this patient?

\section{Treatment}

Surgery remains the mainstay for local or locoregional resectable NETs. With selective low surgical risk patients, early surgical exploration can be considered even in the setting of unknown primary. ${ }^{13}$ There is no clear role of adjuvant radiation or chemotherapy and observation is the preferred approach. Surgical resection can also be considered in metastatic disease with refractory symptoms from hormone secretion. Resection of an asymptomatic primary site in the setting of unresectable metastases is generally not recommended. ${ }^{14}$

For low-volume and asymptomatic unresectable disease, watchful waiting until symptomatic disease or radiological progression is reasonable and acceptable. Consider CT scan in 3 to 4 months to assess tumor growth rate. Low-grade welldifferentiated NETs with very low burden of metastatic disease which is stable on the repeat scan can be watched closely without initiating further systemic therapy and extending the scanning interval to 6 months. However, in symptomatic, functional, moderate-to-high-volume tumors, or tumors with documented radiological growth, treatment initiation should be considered.

SSAs have also been found to provide disease stabilization and PFS benefit. 6,7 These should be considered as first-line therapy due to their favorable side-effect profile and proven benefit in randomized controlled trials. GETNE-TRASGU nomograms could be used to estimate PFS in patient receiving SSA based on other factors, like tumor location, $\mathrm{K}_{\mathrm{i}}-67$ index, and symptoms; however, it is not widely used in the United States. ${ }^{15}$ Benefit of lanreotide and octreotide LAR in advanced well-differentiated nonfunctioning GEP NET was shown in randomized controlled trials (RCTs). ${ }^{16}$ - Table 1 summarizes some key clinical trials in NETs.

... Monthly octreotide LAR was initiated with symptomatic improvement. CT scan after 4 months showed disease progression in liver and new right upper quadrant abdominal pain and worsening right hip pain. What are the treatment options for this patient now?

Liver predominant metastatic disease can be managed with surgical resection, liver transplant, or nonsurgical liverdirected therapies like ablation and embolotherapies. If liver function is adequate and with the feature of a few dominated large liver metastasis in the absence of diffuse involvement of both liver lobes, surgical resection is an option with the goal of a $70 \%$ cytoreduction. This can offer symptom relief and lower rate of disease recurrence. ${ }^{17}$ Nonsurgical procedures like radiofrequency ablation, cryoablation, or microwave ablation can be utilized for oligometastatic liver disease or as an adjunct to surgery. Data for external beam radiation in well-differentiated NETs is limited and is often not used in 


\begin{tabular}{|c|c|c|c|c|c|c|c|c|c|c|c|c|c|c|}
\hline 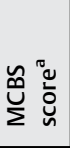 & $\begin{array}{l}\overline{1} \\
\tilde{n} \\
0\end{array}$ & $m$ & $\begin{array}{l}\overline{7} \\
+ \\
m \\
\sigma \\
\sigma\end{array}$ & & $m$ & $m$ & $m$ & $\begin{array}{l}\bar{c} \\
\overline{1} \\
\stackrel{n}{n} \\
\sim\end{array}$ & m & $m$ & & & & 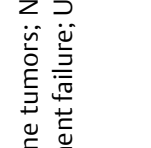 \\
\hline 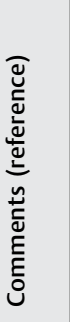 & 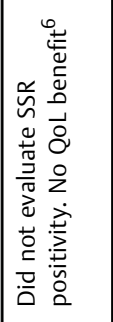 & 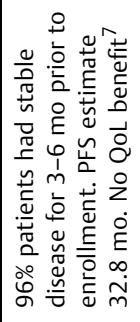 & 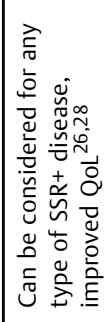 & 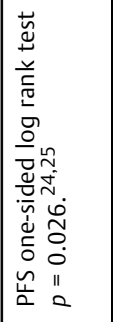 & 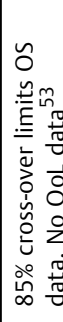 & 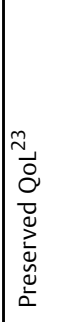 & 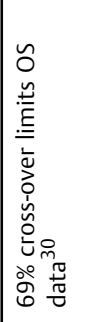 & 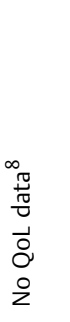 & 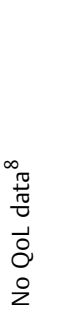 & 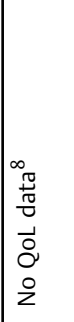 & 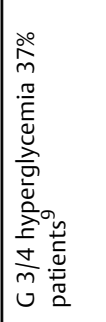 & 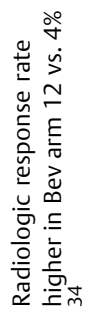 & 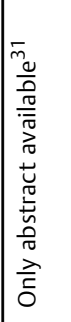 & 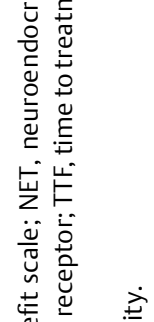 \\
\hline$\tilde{o}$ & 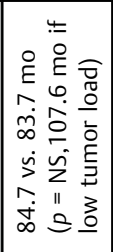 & 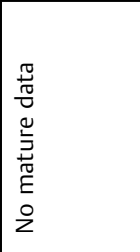 & 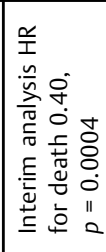 & 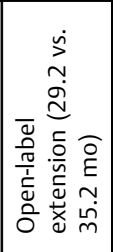 & 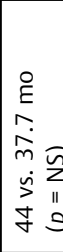 & 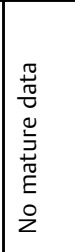 & 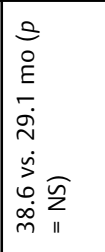 & & & & 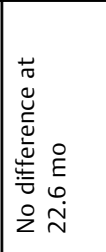 & & 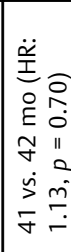 & 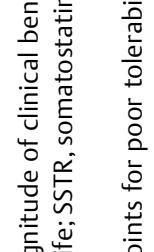 \\
\hline$\underline{\underline{a}}$ & 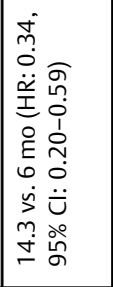 & 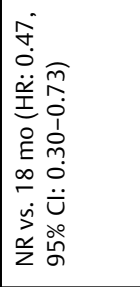 & 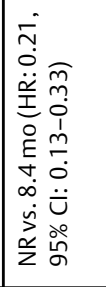 & 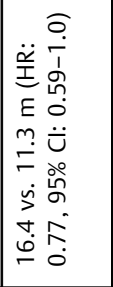 & 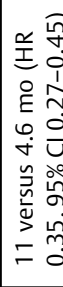 & 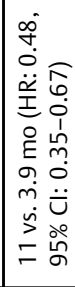 & 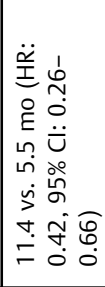 & 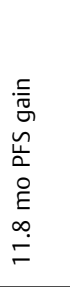 & 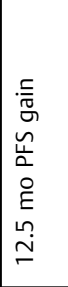 & 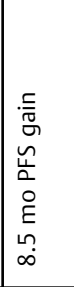 & 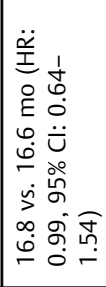 & 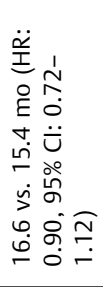 & 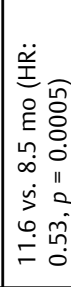 & 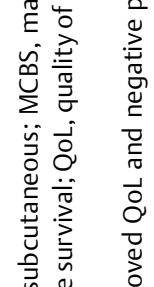 \\
\hline$=$ & 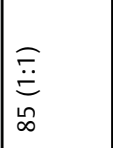 & 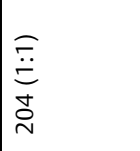 & 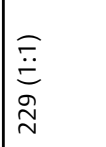 & 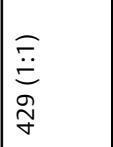 & 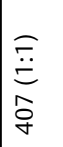 & $\begin{array}{l}\overline{\grave{j}} \\
\tilde{\tilde{d}} \\
\tilde{m}\end{array}$ & 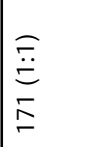 & 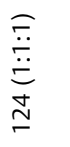 & $\begin{array}{l}\check{\check{C}} \\
\ddot{\check{C}} \\
\stackrel{\sim}{\simeq}\end{array}$ & 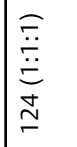 & 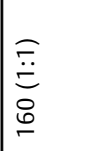 & 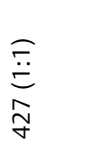 & 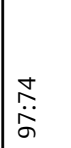 & 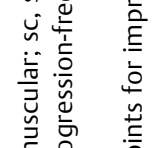 \\
\hline 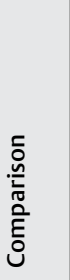 & $\begin{array}{l}0 \\
\stackrel{0}{0} \\
\frac{\pi}{\alpha}\end{array}$ & \begin{tabular}{|l}
0 \\
$\frac{8}{\mathscr{U}}$ \\
$\frac{\pi}{\alpha}$ \\
\end{tabular} & 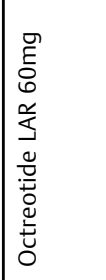 & 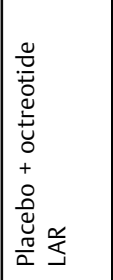 & $\begin{array}{l}0 \\
\stackrel{8}{0} \\
\frac{\pi}{0} \\
\frac{0}{\alpha}\end{array}$ & 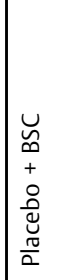 & $\begin{array}{l}\circ \\
\frac{8}{0} \\
\frac{\pi}{\alpha} \\
\frac{\pi}{\alpha}\end{array}$ & 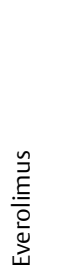 & 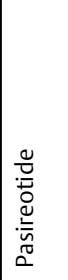 & 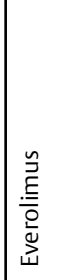 & 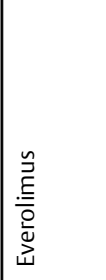 & 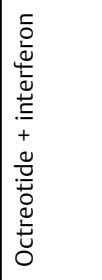 & 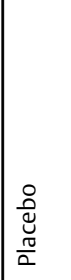 & 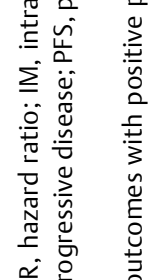 \\
\hline 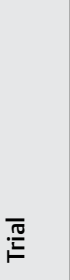 & 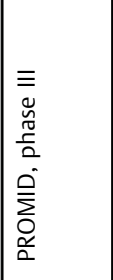 & 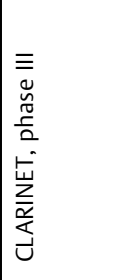 & 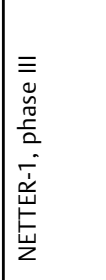 & 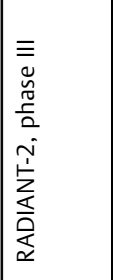 & 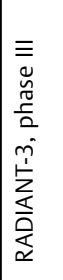 & 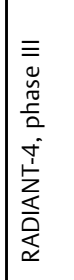 & 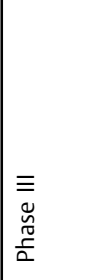 & 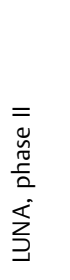 & 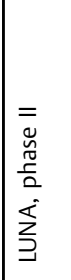 & 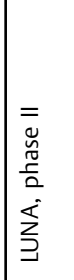 & 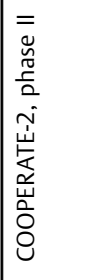 & 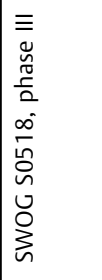 & 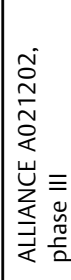 & 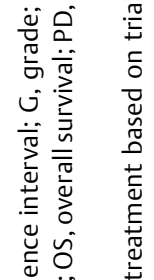 \\
\hline 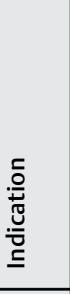 & 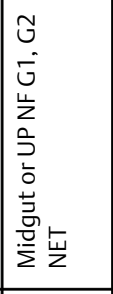 & 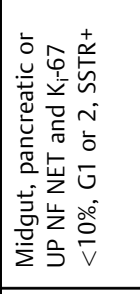 & 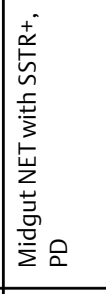 & 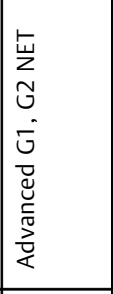 & 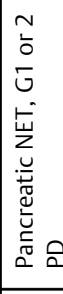 & 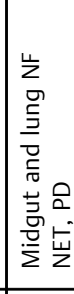 & 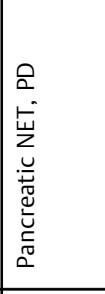 & 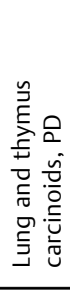 & 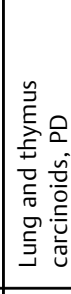 & 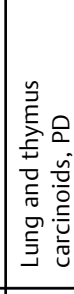 & 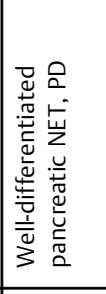 & 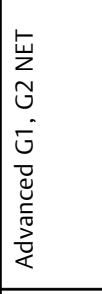 & 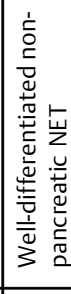 & 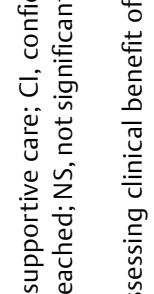 \\
\hline 9 & 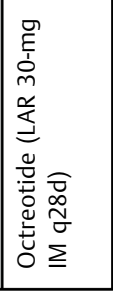 & 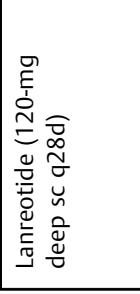 & 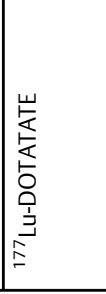 & 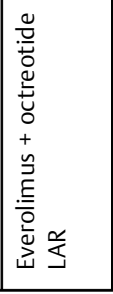 & 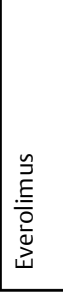 & 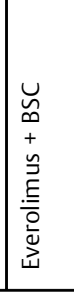 & 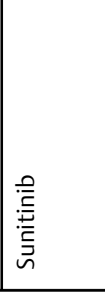 & 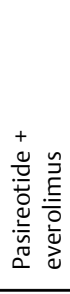 & 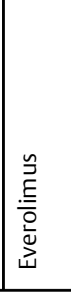 & 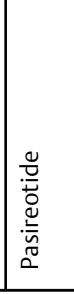 & 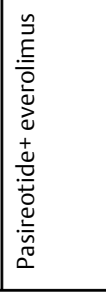 & 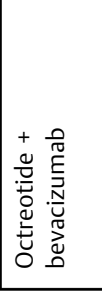 & 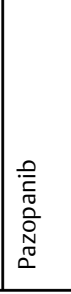 & 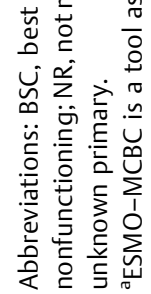 \\
\hline
\end{tabular}



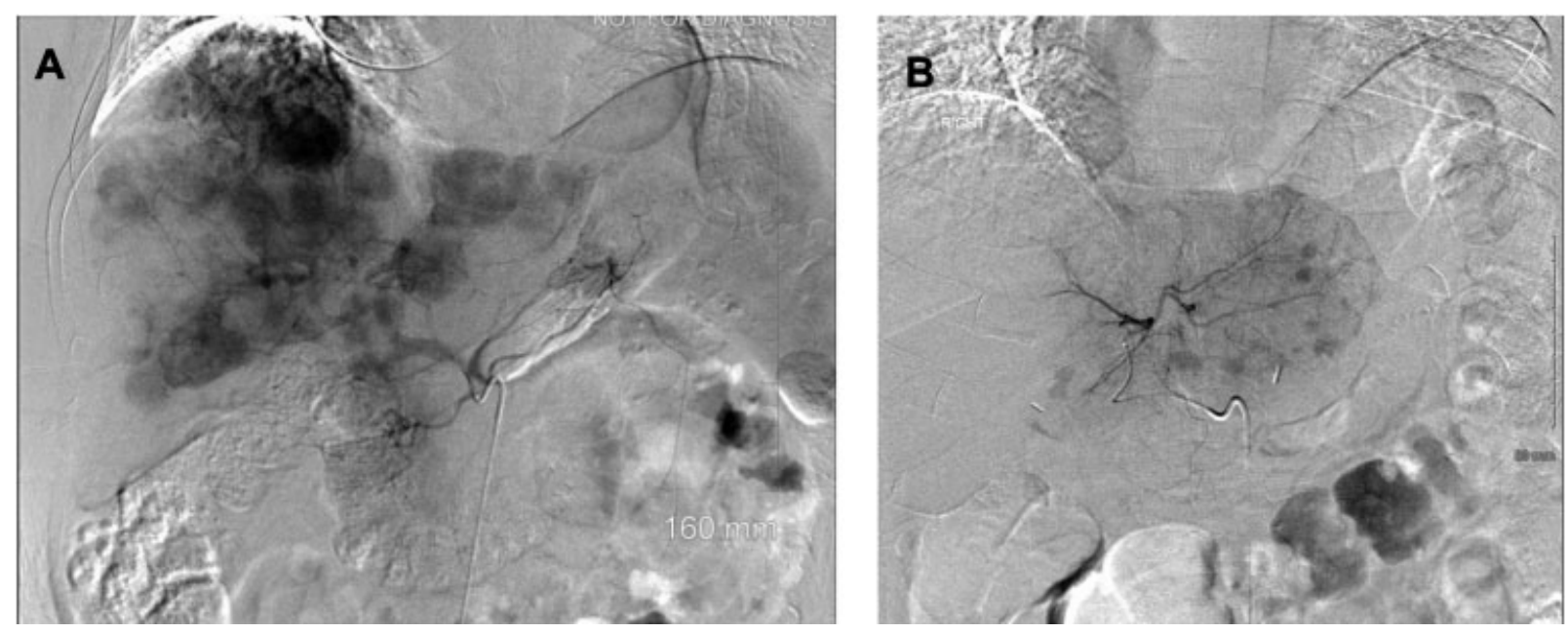

Fig. 1 (A) Celiac artery angiogram demonstrating multiple enhancing metastatic NET throughout the liver. (B) Left hepatic artery angiogram demonstrating enhancing metastatic NET in the left lobe of the liver (representative images; source: Department of Radiology, University of Kentucky). NET, neuroendocrine tumors.

clinical practice. Percutaneous ablative techniques are limited to lesions typically less than $3 \mathrm{~cm}$ in size and generally up to four lesions. However, evidence regarding this is supported only by small case studies. ${ }^{18,19}$ Symptomatic or progressive hepatic predominant unresectable disease can also be treated with bland hepatic arterial embolization, chemoembolization or radioembolization or may be considered as a palliative measure. Transarterial bland embolization (our preferred method) is most commonly performed using bland microspheres (-Fig. 1). Transarterial chemoembolization follows the same principles as bland embolization with the addition of a chemotherapeutic agent. ${ }^{20}$ Radioembolization involves injection of microspheres incorporating the radioisotope Yttrium-90 intra-arterially into the liver. ${ }^{21}$ Although liver transplantation may provide longterm recurrence-free survival in some patients, the majority ultimately develop recurrent disease. ${ }^{22}$

... She underwent right and left lobe liver bland embolization without complication. Also received palliative radiation therapy to the right hip. What systemic therapy is ideal now?

\section{Progression}

In functional NETs, SSAs may be continued for symptom management. Systemic therapy options on progression include everolimus, sunitinib, or Lu-DOTATATE radionuclide therapy (-Table $\mathbf{1}$ ).

Everolimus improves PFS without overall survival (OS) benefit in advanced nonfunctional GI and lung NETs. Grade $1 / 2$ skin, GI side effects, and fatigue were mainly reported. ${ }^{23}$ In advanced G1/2 NETs, treatment with octreotide plus everolimus showed clinically meaningful prolongation of PFS but only trended toward statistical significance. ${ }^{24}$ An open-label extension of the study failed to show any OS benefit as many patients received everolimus off-study. ${ }^{25}$ In our experience, everolimus is active in NETs and is able to stabilize disease in most patients for several months. Oral mucositis can be prevented with prophylactic steroid mouth wash, especially during first 4 to 6 weeks of therapy and dose adjustments are often required.

Peptide receptor radionuclide therapy: The evidence of PFS benefit from radiolabeled SSA, Lu-DOTATATE was demonstrated in NETTER-1 trial with an interim analysis, also demonstrating OS benefit. ${ }^{26}$ Objective response rate was higher among patients on peptide receptor radionuclide therapy PRRT (18 vs. 3\%). The most common side effect was nausea (59\%) from the amino acid infusions administered during treatment for renal protection. Mild cytopenias were also common with nadir counts expected around 4 to 6 weeks after infusion and resolved by 8 weeks. ${ }^{27}$ Later studies also showed improved quality of life. ${ }^{28}$ Patients with G1/2 inoperable and metastatic SSR + NET, with expected survival of $>3$ months, Karnofsky's performance status $>50$, sufficient bone marrow reserve, and creatinine clearance $>50 \mathrm{~mL} / \mathrm{min}$ were included in the clinical trial and should be the ideal candidates for this treatment. The LuDOTATATE is acceptable as second- or third-line treatment option for metastatic progressive midgut and pancreatic NET with SSR expression, although pancreatic NETs were not studied in NETTER-1 phase-III clinical trial. ${ }^{28}$ In our practice, we often consider ${ }^{177} \mathrm{Lu}$-DOTATATE as second line if patient has symptomatic disease, bone metastasis, or need for cytoreduction. Lu-DOTATATE has the most superior PFS and overall recurrence rate (ORR) data among the approved therapies for NETs. It can be potentially deferred to third- or fourth-line treatment option in patients with mesenteric disease, as PRRT often does not work well for peritoneal metastasis and in young patients due to concern for longterm myelotoxicity and less than 5\% long-term risk of myelodysplasias or leukemia. ${ }^{29}$

The presence of SSR can be determined by diagnostic imaging using a radiolabeled SSA Indium-111 pentetreotide (OctreoScan) or PET scan using Gallium-68 DOTATATE. The higher sensitivity of the later one makes it the preferred option, especially in patients with low tumor volume. Uptake of radiolabeled isotope is predictive of response to therapy. 
Tyrosine kinase inhibitors: Although sunitinib, sorafenib, surufatinib, pazopanib, lenvatinib, and cabozantinib have been evaluated in advanced GI-NET in phase- 2 and -3 trials, only sunitinib is currently FDA approved for metastatic progressive pancreatic NETs. ${ }^{30-32}$ In lung and GI-NETs, pazopanib showed PFS improvement compared with placebo without OS benefit. Nintedanib, was evaluated in a phase2 trial for G1/2 NET and was associated with disease stabilization and delayed deterioration of quality of life. ${ }^{33}$

Bevacizumab had a PFS benefit when given with octreotide compared to interferon alfa in a phase-II trial. ${ }^{34}$ However, the confirmatory larger randomized trial with 427 patients failed to show any PFS benefit. ${ }^{35}$ We do not recommend use of bevacizumab in the management of NETs.

Interferon alfa (IFNa) is recommended only if other treatment options are unavailable due to the relatively low level of evidence of benefit and significant side-effect profile. ${ }^{36,37}$ Low-dose IFNa can reduce symptoms of hormonal hypersecretion and result in tumor stabilization in some patients, but tumor regression is rare. ${ }^{34,38,39}$ IFNa is dosed at 3 to $5 \mathrm{MU}$ three times weekly and dose should be titrated to a leukocyte count of $3,000 / \mu \mathrm{L}$. Pegylated IFN (80-150 $\mu \mathrm{g}$ per week subcutaneous) has better tolerability compared with IFNa.
Cytotoxic chemotherapy ( - Table $\mathbf{2}$ ) should be considered in patients with progressive metastatic disease with no standard approved treatment options. Regimens that have shown evidence of activity include capecitabine plus temozolomide (CAPTEM) and short-term infusional $5 \mathrm{FU}$ with leucovorin plus oxaliplatin (FOLFOX); however. confirmatory studies are needed. ${ }^{40,41}$ Based on emerging data and toxicity profile, we consider CAPTEM as the initial chemotherapy regimen especially for G2/3 well-differentiated midgut and pancreatic NET after progression on other treatments. The poor PFS from Eastern Cooperative Oncology Group (ECOG) E1281 trial and toxicity of the drugs have questioned the use of $5 \mathrm{FU}$, streptozocin, and doxorubicin in the treatment of $\mathrm{NET}^{42}$

Immunotherapy: Data on use of immune checkpoint inhibitors are early but promising (-Table 2). Patients with microsatellite unstable tumors and tumor mutational burden $\geq 10$ can now receive pembrolizumab based on available evidence. ${ }^{43}$ DART SWOG 1609 phase-II trial was a basket trial evaluating dual anti-CTLA4 and anti-programmed death 1 (PD1) blockers in rare tumors which showed response mainly in high grade NET. Among the 14 patients with G1/2 NET, 2 had stable disease lasting $>6$

Table 2 Cytotoxic chemotherapy and immunotherapy regimens studied in NETs

\begin{tabular}{|c|c|c|c|c|c|c|c|c|}
\hline Regimen & Trial (year) & $n$ & $\begin{array}{l}\text { CR } \\
(\%)\end{array}$ & $\begin{array}{l}\text { PR } \\
(\%)\end{array}$ & $\begin{array}{l}\text { SD } \\
(\%)\end{array}$ & $\begin{array}{l}\mathrm{mPFS} \\
(\mathrm{mo})\end{array}$ & $\begin{array}{l}\mathrm{mOS} \\
(\mathrm{mo})\end{array}$ & Comments (ref.) \\
\hline Capecitabine & Phase II (2011) & 19 & - & - & 68 & 9.9 & 36.5 & 54 \\
\hline $\begin{array}{l}\text { Capecitabine + } \\
\text { oxaliplatin }\end{array}$ & Phase II (2007) & 27 & - & 30 & 48 & 18 & 32 & 55 \\
\hline Capecitabine + Bev & Phase II (2014) & 49 & - & 18 & 70 & 23.4 & NR & $\begin{array}{l}\text { 2-year OS: } 85 \% \text {; } 82 \% \text { ileal } \\
\text { primary } 56\end{array}$ \\
\hline $\begin{array}{l}5 \mathrm{FU}+\text { streptozocin } \\
5 \mathrm{FU}+\text { doxorubicin } \\
9 \text { PD: dacarbazine }\end{array}$ & $\begin{array}{l}\text { Phase II/III ECOG } \\
\text { E1281 (2005) }\end{array}$ & $\begin{array}{l}78 \\
85\end{array}$ & 2.4 & $\begin{array}{l}16 \\
13.5 \\
8\end{array}$ & $\begin{array}{l}15.4 \\
15.4\end{array}$ & $\begin{array}{l}4.5 \\
5.3\end{array}$ & $\begin{array}{l}24.3 \\
11.9\end{array}$ & $\begin{array}{l}\text { Grades } 1,2 \text { renal toxicity 35\% } \\
\text { with STZ } 42\end{array}$ \\
\hline $\begin{array}{l}\text { FOLFOX + Bev } \\
\text { CAPEOX + Bev }\end{array}$ & Phase II (2016) & $\begin{array}{l}36 \\
40\end{array}$ & - & $\begin{array}{l}25 \\
18\end{array}$ & $\begin{array}{l}69.4 \\
60\end{array}$ & $\begin{array}{l}21 \\
19.1\end{array}$ & $\begin{array}{l}31 \\
42.2\end{array}$ & $\begin{array}{l}\text { Included } 6 \text { NEC. Did not meet } \\
\text { 1-degree endpoint. }{ }^{41}\end{array}$ \\
\hline TMZ & Retrospective (2007) & 36 & - & 14 & 53 & 7 & 16 & 57 \\
\hline TMZ & Retrospective (2013) & 31 & - & 14 & 52 & 5.3 & 23.2 & Only bronchial carcinoids ${ }^{58}$ \\
\hline Capecitabine + TMZ & Retrospective (2013) & 18 & 5.5 & 55.5 & 22.2 & 14 & 83 & $\begin{array}{l}\text { Only patients with liver } \\
\text { metastasis }\end{array}$ \\
\hline Capecitabine + TMZ & Phase II (2014) & 28 & 11 & 32 & 54 & $>20$ & NR & Abstract only ${ }^{60}$ \\
\hline Capecitabine + TMZ & Retrospective (2011) & 30 & - & 70 & 27 & 18 & - & $\begin{array}{l}\text { 2-year OS: } 92 \% . \text { Only } \\
\text { pancreatic NET }\end{array}$ \\
\hline $\mathrm{TMZ}+\mathrm{Bev}$ & Phase II (2012) & 34 & - & 15 & 65 & 11 & 33.3 & $\begin{array}{l}\text { Most of the benefit seen in } \\
\text { pancreatic NET }\end{array}$ \\
\hline Pembrolizumab & $\begin{array}{l}\text { Phase I KEYNOTE-028 } \\
(2020)\end{array}$ & 41 & - & 9.7 & 70.7 & $5.6 / 4.5^{\mathrm{a}}$ & - & PDL1 positive tumors only ${ }^{63}$ \\
\hline Pembrolizumab & $\begin{array}{l}\text { Phase II KEYNOTE -158 } \\
(2020)\end{array}$ & 107 & - & 3.7 & 56.1 & 4.1 & 24.2 & $\begin{array}{l}\text { All PR in PDL1 negative } \\
\text { tumors. } 64\end{array}$ \\
\hline $\begin{array}{l}\text { Ipilimumab + } \\
\text { Nivolumab }\end{array}$ & $\begin{array}{l}\text { Phase II DART SWOG } \\
1609(2020)\end{array}$ & 32 & 3 & 22 & 41 & 4 & 11 & $\begin{array}{l}\text { Only nonpancreatic NET. 56\% } \\
\text { NEC }^{44}\end{array}$ \\
\hline
\end{tabular}

Abbreviations: Bev, bevacizumab; CR, complete response; FOLFOX, FU with leucovorin plus oxaliplatin; CAPEOX, capecitabine plus oxaliplatin; NEC, neuroendocrine carcinoma; NET, neuroendocrine tumors; OS, overall survival; PDL1, programmed death ligand 1; PFS, progression-free survival; PR, partial response; SD, stable disease; STZ, streptozocin; TMZ, temozolomide.

a5.6 months for carcinoids and 4.5 months for pancreatic NET. 
months with no complete response (CR) or partial response (PR). ${ }^{44}$

... She was then started on everolimus along with octreotide LAR and dose titrated to 10-mg daily. Two months later, she complained about worsening episodes of sweating, flushing, and dizziness, however, not associated with diarrhea or nausea. Blood work in clinic showed glucose levels of 43 which improved with oral glucose administration. Her abdominal pain and hip pain had improved and did not require any further opioid pain medications. Dietary education was given and continued having frequent laboratory checks.

It is important to understand the side-effect profile of each drug while choosing between two treatments. Although both everolimus and octreotide can inhibit insulin leading to hyperglycemia, especially in diabetic patients, both the drugs can cause paradoxical hypoglycemia by decreasing secretion of hormones for glycogenolysis and gluconeogenesis. SSAs are well tolerated with only onethird of patients developing mild symptoms of bloating, diarrhea, and nausea which improves with time. ${ }^{25}$ Use of pancreatic enzyme supplementation help resolve some symptoms. ${ }^{45}$ Also, 25\% of patients may develop asymptomatic gallstones due to delayed gall bladder emptying. Equally important is to know the complications of SSA discontinuation, like carcinoid crisis, and long-term effects, like carcinoid heart syndrome, making it important to continue SSA beyond progression.

... 3 months later, Ga-68 DOTATATE scan demonstrated improvement in hepatic lesions but new areas of bone involvement including multiple vertebral bodies. She was started on PRRT. She tolerated the treatment well. Repeat Ga-68 DOTATATE scan after four doses of PRRT showed decreased avidity of skeletal lesions and no new lesions.

\section{Case 2}

A 52-year-old male initially presented with severe abdominal and back pain. CT showed multiple liver lesions. Fluorodeoxyglucose (FDG)-PET/CT confirmed hypermetabolic liver lesions, pancreatic cystic lesion, T11-L1 vertebral lesions, and portocaval lymphadenopathy. Biopsy of liver lesion showed G3 well-differentiated pancreatic NET with $\mathrm{K}_{\mathrm{i}}$ 67 of $30 \%$. He completed four cycles of cisplatin and etoposide with stabilization of disease. However, there was disease progression after 5 months of treatment completion. What is the ideal treatment for this patient?

The recent WHO classification for GEP NETs recognizes a new category of high-grade neuroendocrine neoplasm called G3 well-differentiated NETs. ${ }^{2}$ By definition, G3 NETs will have $\mathrm{K}_{\mathrm{i}}-67>20 \%$. However, $\mathrm{K}_{\mathrm{i}}-67$ typically ranges between 20 and $55 \%$ for this subset of tumors. G3 NETs often show SSR imaging positivity and are typically of pancreatic origin. ${ }^{46}$ Thus, the clinical behavior is between poorly differentiated neuroendocrine carcinoma and G2 well-differentiated NET. ${ }^{47}$ While $92 \%$ high-grade tumors are PET avid, SSR-based imaging may be more helpful in NET G3. ${ }^{48,49}$
Patients with advanced, well-differentiated G3 NETs do not often respond to platinum-etoposide regimen as with high-grade poorly differentiated NEC. ${ }^{50}$ Hence, treatment with carboplatin or cisplatin with etoposide is preferred only in very aggressive disease and on disease progression. Treatments used in low-to-intermediate grade NETs like capecitabine-temozolomide- or streptozocin-based chemotherapy or sunitinib is preferred as first-line therapy. Whenever possible, these patients should be encouraged to enroll in clinical trials as evidence is not clear due to exclusion of these patients from most of the clinical trials. ECOG-ACRIN EA2142 trial is currently evaluating capecitabine-temozolomide regimen versus cisplatin etoposide in NET G3 (ClinicalTrials.gov ID: NCT02595424). PRRT should be considered in NET G3 with high SSR uptake. Currently, no prospective data exist to support this, as this is extremely rare subset of NETs; however, presence of somatostatin receptor-2 (SSTR-2) makes PRRT a lucrative treatment option. Everolimus showed median progression free survival ( $\mathrm{MPFS}$ ) of 6 months and median overall survival (mOS) of 28 months after drug initiation in a series of 15 patients with NET G3. ${ }^{51}$ Most of the patients received it as second-line treatment and median $\mathrm{K}_{\mathrm{i}}$ 67 was $30 \%$ in this study.

... Patient then received capecitabine plus temozolomide for 6 months. On disease progression, he was switched to everolimus. With SSR positivity on Ga-68 DOTATATE scan, patient was started on Lu-177 DOTATATE but progressed after four cycles. He was then initiated on sunitinib and due to intolerance, transitioned to off-label ipilimumab plus nivolumab.

\section{Practical Recommendations}

Following an evidence-based approach will provide maximum clinical benefit for patients without overt expenditure. Some of the practical recommendations are listed below:

- Indolent nature of the disease should be considered when choosing initial therapies. Observation and SSA analogs may be appropriate in asymptomatic stable disease.

- Blood-based biomarkers like chromogranin A have poor sensitivity and specificity.

- Baseline brain imaging is usually not required for staging. Multiphasic liver imaging and oral contrast for bowel evaluation can be done along with SSR-PET/CT in a single setting.

- Routine use of gallium-68-DOTATATE PET/CT for disease monitoring should be avoided. CT/MR are most reliable methods for radiological monitoring. FDG-PET should be used in NEC.

- There are indigenous SSR-directed PRRT therapeutics available in some low- to middle-income countries (LMICs) at a reduced cost, although no comparison on trials are available with standard product. ${ }^{52}$

- Networking with NET specialist for a second opinion and referring to consensus North American Neuroendocrine Tumor Society (NANETS) and European Society of Neuroendocrine Tumors (ENETS) guidelines is encouraged. 


\section{Conclusion}

NETs are heterogeneous and rare tumors often posing challenging management dilemmas. A multidisciplinary approach is endorsed for their initial management. The discussion focused on medical management and a detailed analysis of the surgical modalities and nonsurgical procedures are outside the purview of this review. Due to the wide range of clinical behavior and treatment responses with NETs, treatment should always be individualized. Being a rare tumor with limited randomized controlled data available, clinical trial participation is encouraged. We recommend referring to the National Comprehensive Cancer Network (NCCN), NANETS, and ENETS guidelines for updated management options that may change as results from ongoing trials are published.

\section{Financial Disclosures}

A.C. receives research support from BMS, Clovis Oncology, EMD Serono, Nanopharmaceuticals, Tersera, ECS Progastrin. Advisor: Novartis, Ipsen, TerSera, Lexicon, Seneca Therapeutics, and ECS Progastrin. R.A.R. serves as a speaker for Merck \& Co., Inc., Advanced Accelerator Applications, Genentech, Inc., AstraZeneca, and Ipsen Biopharmaceuticals, Inc. Consultant for Curium Pharma, Advanced Accelerator Applications, AstraZeneca, Ipsen Biopharmaceuticals and Novartis Pharmaceuticals, Corp. Research funding from Aadi Biosciences, and Merck \& Co., Inc. Other coauthors do not have relevant disclosures.

\section{Conflict of Interest}

L.A. reports grants from Lexicon Pharmaceuticals, Inc., Entrinsic Health, Inc., and personal fees from Sun Pharmaceuticals, Inc., during the conduct of the study. A.C. reports grants from BMS, EMD Serono, Nanopharmaceuticals, and Clovis; other from Ipsen, Novartis, Lexicon, TerSera; and nonfinancial support from ECS Progastrin, during the conduct of the study. R.A.R. reports personal fees from Ipsen Biopharmaceuticals, Novartis, Curium, Advanced Accelerator Applications, Genentech, Astra Zeneca, grants and personal fees from Merck, and grants from Aadi Bioscience, outside the submitted work.

\section{References}

1 Yao JC, Hassan M, Phan A, et al. One hundred years after "carcinoid": epidemiology of and prognostic factors for neuroendocrine tumors in 35,825 cases in the United States. J Clin Oncol 2008;26 (18):3063-3072

2 Nagtegaal ID, Odze RD, Klimstra D, et al. WHO Classification of Tumours Editorial Board. The 2019 WHO classification of tumours of the digestive system. Histopathology 2020;76(02):182-188

3 Catena L, Bichisao E, Milione M, et al. Neuroendocrine tumors of unknown primary site: gold dust or misdiagnosed neoplasms? Tumori 2011;97(05):564-567

4 Sjöblom SM. Clinical presentation and prognosis of gastrointestinal carcinoid tumours. Scand J Gastroenterol 1988;23(07):779-787

5 Seregni E, Ferrari L, Bajetta E, Martinetti A, Bombardieri E. Clinical significance of blood chromogranin A measurement in neuroendocrine tumours. Ann Oncol 2001;12(Suppl 2 S69-S72
6 Rinke A, Wittenberg M, Schade-Brittinger C, et al. PROMID Study Group. Placebo-controlled, double-blind, prospective, randomized study on the effect of octreotide LAR in the control of tumor growth in patients with metastatic neuroendocrine midgut tumors (PROMID): results of long-term survival. Neuroendocrinology 2017;104(01):26-32

7 Vinik AI, Wolin EM, Liyanage N, Gomez-Panzani E, Fisher GA ELECT Study Group. Evaluation of lanreotide depot/autogel efficacy and safety as a carcinoid syndrome treatment (elect): a randomized, double-blind, placebo-controlled trial. Endocr Pract 2016;22(09):1068-1080

8 Ferolla P, Brizzi MP, Meyer T, et al. Efficacy and safety of longacting pasireotide or everolimus alone or in combination in patients with advanced carcinoids of the lung and thymus (LUNA): an open-label, multicentre, randomised, phase 2 trial. Lancet Oncol 2017;18(12):1652-1664

9 Kulke MH, Ruszniewski P, Van Cutsem E, et al. A randomized, open-label, phase 2 study of everolimus in combination with pasireotide LAR or everolimus alone in advanced, well-differentiated, progressive pancreatic neuroendocrine tumors: COOPERATE-2 trial. Ann Oncol 2019;30(11):1846

10 Kulke MH, Hörsch D, Caplin ME, et al. Telotristat ethyl, a tryptophan hydroxylase inhibitor for the treatment of carcinoid syndrome. J Clin Oncol 2017;35(01):14-23

11 Frank M, Klose KJ, Wied M, Ishaque N, Schade-Brittinger C, Arnold R. Combination therapy with octreotide and alpha-interferon: effect on tumor growth in metastatic endocrine gastroenteropancreatic tumors. Am J Gastroenterol 1999;94(05):1381-1387

12 Frankton S, Bloom SR. Gastrointestinal endocrine tumours. Glucagonomas. Baillieres Clin Gastroenterol 1996;10(04):697-705

13 Wang YZ, Chauhan A, Rau J, et al. Neuroendocrine tumors (NETs) of unknown primary: is early surgical exploration and aggressive debulking justifiable? Linchuang Zhongliuxue Zazhi 2016;5(01): 4

14 Lesurtel M, Nagorney DM, Mazzaferro V, Jensen RT, Poston GJ. When should a liver resection be performed in patients with liver metastases from neuroendocrine tumours? A systematic review with practice recommendations. HPB (Oxford 2015;17(01): $17-22$

15 Carmona-Bayonas A, Jiménez-Fonseca P, Lamarca Á, et al. Prediction of progression-free survival in patients with advanced, welldifferentiated, neuroendocrine tumors being treated with a somatostatin analog: the GETNE-TRASGU study. J Clin Oncol 2019; 37(28):2571-2580

16 Caplin ME, Pavel M, Ćwikła JB, et al.CLARINET Investigators. Lanreotide in metastatic enteropancreatic neuroendocrine tumors. N Engl J Med 2014;371(03):224-233

17 Glazer ES, Tseng JF, Al-Refaie W, et al. Long-term survival after surgical management of neuroendocrine hepatic metastases. HPB (Oxford 2010;12(06):427-433

18 Wessels FJ, Schell SR. Radiofrequency ablation treatment of refractory carcinoid hepatic metastases. J Surg Res 2001;95 (01):8-12

19 Berber E, Flesher N, Siperstein AE. Laparoscopic radiofrequency ablation of neuroendocrine liver metastases. World J Surg 2002; 26(08):985-990

20 Kennedy A, Bester L, Salem R, Sharma RA, Parks RW, Ruszniewski P NET-Liver-Metastases Consensus Conference. Role of hepatic intra-arterial therapies in metastatic neuroendocrine tumours (NET): guidelines from the NET-Liver-Metastases Consensus Conference. HPB (Oxford 2015;17(01):29-37

21 Kennedy AS, Dezarn WA, McNeillie P, et al. Radioembolization for unresectable neuroendocrine hepatic metastases using resin 90Ymicrospheres: early results in 148 patients. Am J Clin Oncol 2008; 31(03):271-279

22 Moris D, Tsilimigras DI, Ntanasis-Stathopoulos I, et al. Liver transplantation in patients with liver metastases from 
neuroendocrine tumors: a systematic review. Surgery 2017;162 (03):525-536

23 Yao JC, Fazio N, Singh S, et al. RAD001 in Advanced Neuroendocrine Tumours, Fourth Trial (RADIANT-4) Study Group. Everolimus for the treatment of advanced, non-functional neuroendocrine tumours of the lung or gastrointestinal tract (RADIANT-4): a randomised, placebo-controlled, phase 3 study. Lancet 2016;387(10022) 968-977

24 Pavel ME, Hainsworth JD, Baudin E, et al. RADIANT-2 Study Group. Everolimus plus octreotide long-acting repeatable for the treatment of advanced neuroendocrine tumours associated with carcinoid syndrome (RADIANT-2): a randomised, placebo-controlled, phase 3 study. Lancet 2011;378(9808) 2005-2012

25 Pavel ME, Baudin E, Öberg KE, et al. Efficacy of everolimus plus octreotide LAR in patients with advanced neuroendocrine tumor and carcinoid syndrome: final overall survival from the randomized, placebo-controlled phase 3 RADIANT-2 study. Ann Oncol 2017;28(07):1569-1575

26 Strosberg J, El-Haddad G, Wolin E, et al.NETTER-1 Trial Investigators. Phase 3 trial of 177Lu-Dotatate for midgut neuroendocrine tumors. N Engl J Med 2017;376(02):125-135

27 Brabander T, van der Zwan WA, Teunissen JJ, et al. Long-term efficacy, survival, and safety of [177Lu-DOTAOTyr3]octreotate in patients with gastroenteropancreatic and bronchial neuroendocrine tumors. Clin Cancer Res 2017;23(16):4617-4624

28 Strosberg J, Wolin E, Chasen B, et al. NETTER-1 Study Group. Health-related quality of life in patients with progressive midgut neuroendocrine tumors treated with $177 \mathrm{Lu}$-Dotatate in the phase III NETTER-1 trial. J Clin Oncol 2018;36(25):2578-2584

29 Sonbol MB, Halfdanarson TR, Hilal T. Assessment of therapyrelated myeloid neoplasms in patients with neuroendocrine tumors after peptide receptor radionuclide therapy: a systematic review. JAMA Oncol 2020;6(07):1086-1092

30 Kulke MH, Lenz HJ, Meropol NJ, et al. Activity of sunitinib in patients with advanced neuroendocrine tumors. J Clin Oncol 2008;26(20):3403-3410

31 Grande E, Capdevila J, Castellano D, et al. Pazopanib in pretreated advanced neuroendocrine tumors: a phase II, open-label trial of the Spanish Task Force Group for Neuroendocrine Tumors (GETNE. Ann Oncol 2015;26(09):1987-1993

32 Capdevila J, Fazio N, Lopez CL, et al. Final results of the TALENT trial (GETNE1509): a prospective multicohort phase II study of lenvatinib in patients (pts) with G1/G2 advanced pancreatic (panNETs) and gastrointestinal (giNETs) neuroendocrine tumors (NETs. J Clin Oncol 2019;37(15suppl) 4106

33 Iyer RV, Konda B, Fountzilas C, et al. Multicenter phase 2 trial of nintedanib in advanced nonpancreatic neuroendocrine tumors. Cancer 2020;126(16):3689-3697

34 Yao JC, Phan A, Hoff PM, et al. Targeting vascular endothelial growth factor in advanced carcinoid tumor: a random assignment phase II study of depot octreotide with bevacizumab and pegylated interferon alpha-2b. J Clin Oncol 2008;26(08):1316-1323

35 Yao JC, Guthrie KA, Moran C, et al. Phase III prospective randomized comparison trial of depot octreotide plus interferon Alfa-2b versus depot octreotide plus bevacizumab in patients with advanced carcinoid tumors: SWOG S0518. J Clin Oncol 2017;35(15): 1695-1703

36 Strosberg JR, Halfdanarson TR, Bellizzi AM, et al. The North American Neuroendocrine Tumor Society Consensus Guidelines for surveillance and medical management of midgut neuroendocrine tumors. Pancreas 2017;46(06):707-714

37 Pavel M, O'Toole D, Costa F, et al.Vienna Consensus Conference participants. ENETS consensus guidelines update for the management of distant metastatic disease of intestinal, pancreatic, bronchial neuroendocrine neoplasms (NEN) and NEN of unknown primary site. Neuroendocrinology 2016;103(02):172-185

38 Faiss S, Pape UF, Böhmig M, et al. International Lanreotide and Interferon Alfa Study Group. Prospective, randomized, multicen- ter trial on the antiproliferative effect of lanreotide, interferon alfa, and their combination for therapy of metastatic neuroendocrine gastroenteropancreatic tumors-the International Lanreotide and Interferon Alfa Study Group. J Clin Oncol 2003;21(14): 2689-2696

39 Arnold R, Rinke A, Klose KJ, et al. Octreotide versus octreotide plus interferon-alpha in endocrine gastroenteropancreatic tumors: a randomized trial. Clin Gastroenterol Hepatol 2005;3(08): 761-771

40 Al-Toubah T, Morse B, Strosberg J. Capecitabine and temozolomide in advanced lung neuroendocrine neoplasms. Oncologist 2020;25(01):e48-e52

41 Kunz PL, Balise RR, Fehrenbacher L, et al. Oxaliplatin-fluoropyrimidine chemotherapy plus bevacizumab in advanced neuroendocrine tumors: an analysis of 2 phase II trials. Pancreas 2016;45 (10):1394-1400

42 Sun W, Lipsitz S, Catalano P, Mailliard JA, Haller DG Eastern Cooperative Oncology Group. Phase II/III study of doxorubicin with fluorouracil compared with streptozocin with fluorouracil or dacarbazine in the treatment of advanced carcinoid tumors: Eastern Cooperative Oncology Group Study E1281. J Clin Oncol 2005;23(22):4897-4904

43 Marabelle A, Le DT, Ascierto PA, et al. Efficacy of pembrolizumab in patients with noncolorectal high microsatellite instability/mismatch repair-deficient cancer: results from the phase II KEYNOTE-158 study. J Clin Oncol 2020;38(01):1-10

44 Patel SP, Othus M, Chae YK, et al. A phase II basket trial of dual antiCTLA-4 and anti-PD-1 blockade in rare tumors (DART SWOG 1609 ) in patients with nonpancreatic neuroendocrine tumors. Clin Cancer Res 2020;26(10):2290-2296

45 Newman CB, Melmed S, Snyder PJ, et al. Safety and efficacy of long-term octreotide therapy of acromegaly: results of a multicenter trial in 103 patients-a clinical research center study. J Clin Endocrinol Metab 1995;80(09):2768-2775

46 Coriat R, Walter T, Terris B, Couvelard A, Ruszniewski P. Gastroenteropancreatic Well-differentiated grade 3 neuroendocrine tumors: review and position statement. Oncologist 2016;21 (10):1191-1199

47 Basturk O, Yang Z, Tang LH, et al. The high-grade (WHO G3) pancreatic neuroendocrine tumor category is morphologically and biologically heterogenous and includes both well differentiated and poorly differentiated neoplasms. Am J Surg Pathol 2015; 39(05):683-690

48 Walter T, Tougeron D, Baudin E, et al.CEPD investigators. Poorly differentiated gastro-entero-pancreatic neuroendocrine carcinomas: Are they really heterogeneous? Insights from the FFCD-GTE national cohort. Eur J Cancer 2017;79; 158-165

49 Heetfeld M, Chougnet CN, Olsen IH, et al. other Knowledge Network members. Characteristics and treatment of patients with G3 gastroenteropancreatic neuroendocrine neoplasms. Endocr Relat Cancer 2015;22(04):657-664

50 Hijioka S, Hosoda W, Matsuo K, et al. Rb Loss and KRAS mutation are predictors of the response to platinum-based chemotherapy in pancreatic neuroendocrine neoplasm with grade 3: a Japanese multicenter pancreatic NEN-G3 study. Clin Cancer Res 2017;23 (16):4625-4632

51 Panzuto F, Merola E, Pavel ME, et al. Stage IV gastro-enteropancreatic neuroendocrine neoplasms: a risk score to predict clinical outcome. Oncologist 2017;22(04):409-415

52 Basu SPR, Ranade R, Thapa P. Peptide receptor radionuclide therapy in the management of neuroendocrine tumors (Neoplasms)*: Fundamentals and salient clinical practice points for medical oncologists. Indian J Med Paediatr Oncol 2019;40; 165-167

53 Yao JC, Pavel M, Lombard-Bohas C, et al. Everolimus for the treatment of advanced pancreatic neuroendocrine tumors: overall survival and circulating biomarkers from the randomized, phase III RADIANT-3 study. J Clin Oncol 2016;34(32):3906-3913 
54 Medley L, Morel AN, Farrugia D, et al. Phase II study of single agent capecitabine in the treatment of metastatic non-pancreatic neuroendocrine tumours. Br J Cancer 2011;104(07):1067-1070

55 Bajetta E, Catena L, Procopio G, et al. Are capecitabine and oxaliplatin (XELOX) suitable treatments for progressing lowgrade and high-grade neuroendocrine tumours? Cancer Chemother Pharmacol 2007;59(05):637-642

56 Mitry E, Walter T, Baudin E, et al. Bevacizumab plus capecitabine in patients with progressive advanced well-differentiated neuroendocrine tumors of the gastro-intestinal (GI-NETs) tract (BETTER trial)-a phase II non-randomised trial. Eur J Cancer 2014;50(18): 3107-3115

57 Ekeblad S, Sundin A, Janson ET, et al. Temozolomide as monotherapy is effective in treatment of advanced malignant neuroendocrine tumors. Clin Cancer Res 2007;13(10):2986-2991

58 Crona J, Fanola I, Lindholm DP, et al. Effect of temozolomide in patients with metastatic bronchial carcinoids. Neuroendocrinology 2013;98(02):151-155

59 Fine RL, Gulati AP, Krantz BA, et al. Capecitabine and temozolomide (CAPTEM) for metastatic, well-differentiated neuroendo- crine cancers: The Pancreas Center at Columbia University experience. Cancer Chemother Pharmacol 2013;71(03):663-670

60 Fine RL, Gulati AP, Tsushima D, et al. Prospective phase II study of capecitabine and temozolomide (CAPTEM) for progressive, moderately, and well-differentiated metastatic neuroendocrine tumors. J Clin Oncol 2014;32(Suppl 3179

61 Strosberg JR, Fine RL, Choi J, et al. First-line chemotherapy with capecitabine and temozolomide in patients with metastatic pancreatic endocrine carcinomas. Cancer 2011;117(02):268-275

62 Chan JA, Stuart K, Earle CC, et al. Prospective study of bevacizumab plus temozolomide in patients with advanced neuroendocrine tumors. J Clin Oncol 2012;30(24):2963-2968

63 Mehnert JM, Bergsland E, O'Neil BH, et al. Pembrolizumab for the treatment of programmed death-ligand 1-positive advanced carcinoid or pancreatic neuroendocrine tumors: results from the KEYNOTE-028 study. Cancer 2020;126(13):3021-3030

64 Strosberg J, Mizuno N, Doi T, et al. Efficacy and safety of pembrolizumab in previously treated advanced neuroendocrine tumors: results from the phase II KEYNOTE-158 study. Clin Cancer Res 2020;26(09):2124-2130 